\title{
Investigating the Compatibility of Various Components in Marine Low-Sulfur Fuel Oil by Molecular Dynamics Simulations
}

\author{
Daping Zhou $\mathbb{D}^{1},{ }^{1}$ Haijun Wei $\mathbb{D}^{1},{ }^{1}$ Shuye Xue, ${ }^{1}$ Ye Qiu, ${ }^{1}$ Shen $W u,{ }^{2}$ and Haijie Yu ${ }^{1}$ \\ ${ }^{1}$ Merchant Marine College, Shanghai Maritime University, Shanghai 201306, China \\ ${ }^{2}$ Institute of Power Plants and Automation, Shanghai Jiaotong University, Shanghai 200240, China \\ Correspondence should be addressed to Haijun Wei; hjwei@shmtu.edu.cn
}

Received 15 May 2021; Revised 24 August 2021; Accepted 28 August 2021; Published 17 September 2021

Academic Editor: Florent Barbault

Copyright ( 2021 Daping Zhou et al. This is an open access article distributed under the Creative Commons Attribution License, which permits unrestricted use, distribution, and reproduction in any medium, provided the original work is properly cited.

Asphaltene aggregation and precipitation are one of the major issues for marine low-sulfur fuel oil used on board. Many research studies have been carried out to investigate the aggregation behavior of asphaltene under different conditions, but the mechanism of asphaltene aggregation in low-sulfur fuel oil at the molecular level is still unclear. In this work, molecular dynamics (MD) simulations were performed to calculate the solubility parameters, intermolecular interaction energies, and radial distribution function (RDF) curves of each component in marine low-sulfur fuel oil to examine their mutual compatibility. Simulation results indicate that the solubility parameter of resin gains the highest value and it is close to asphaltene. The solubility parameters of aromatic, hexadecane, and saturate decrease successively. The interaction energy between resin and asphaltene molecules is higher than that between the same kind of molecules, which means that resin can inhibit the aggregation of asphaltene molecules. Typically, a light distillate component (hexadecane) is added to heavy fuel oil to yield low-sulfur oil, and our calculations reveal that this has a negative effect on asphaltene aggregation. Specifically, asphaltene is more likely to self-aggregate, as shown by the increase in peak height in the radial distribution function of the asphaltene-asphaltene pair. The findings of this study will provide theoretical support for the production of marine low-sulfur fuel.

\section{Introduction}

With the increasingly stringent requirements on global environmental protection, many countries have imposed strict restrictions on the sulfur content of marine fuel oil. According to the latest requirements made by the International Maritime Organization (IMO), from the beginning of January 1, 2020, all ocean-going vessels that do not equip with desulfurization equipment must use low-sulfur fuel oil with a sulfur content of no more than $0.5 \%(\mathrm{w} / \mathrm{w})$ [1-4]. Furthermore, the sulfur content of fuel oil used in emission control areas should be lower than $0.1 \%[5,6]$. Today, only a few ships have installed the scrubber systems, which means most ocean-going vessels must use the low-sulfur fuel oil to comply with the SOx emission regulation [7]. However, since the introduction of low-sulfur fuel oil to the market, the number of ships plagued by engine failure has increased significantly, and most of the engine failures are related to the clogged fuel oil filters caused by poor stability of the lowsulfur fuel oil [8]. In particular, asphaltene aggregation and precipitation are the main factors related to fuel oil instability issues [9].

Therefore, studies of methods to improve the quality and stability of low-sulfur fuel oil have become increasingly popular, especially measures to inhibit asphaltene, a large fused-ring aromatic component, precipitation [10-13]. In recent years, computer simulation technology has developed rapidly and it has been widely applied in the petrochemical field. Compared with traditional experimental methods, molecular simulation technology has significant advantages. For example, it can reveal the nature of a molecule's interaction from a microperspective, and it can also predict the properties of different chemical compounds without spending a lot of time and cost on experiments [14-17].

To develop a successful research method, a thorough understanding of the interaction of asphaltene with other 
fractions in low-sulfur fuel oil is required. It has been reported that the asphaltene aggregation can be influenced by the intermolecular charge transfer, electrostatic Coulombic interaction, van der Waals interaction, exchange-repulsion interaction, hydrogen bonding, and $\pi-\pi$ interactions [18]. Many studies have been reported in the literature about the intermolecular interactions of asphaltene with other fractions. Rogel et al. [19] studied the asphaltene aggregation behavior in the crude oil and calculated the solubility parameters of different asphaltene models by molecular dynamics simulations. However, due to the computational capacity limitation at that time, only few molecules could be added in the simulation box, which cannot reveal the nature of asphaltene interactions. Amin Tirjooet al. [20] adopted the molecular dynamics simulations to calculate the solubility parameters of various polar, nonpolar, and hydrogenbonded organic solutions. Compared with experimental results, they found that the deviation for non-hydrogenbonded solutions is negligible. Mohammadali et al. [21] investigated the mechanism of different types of asphaltene inhibitors on asphaltene aggregation by MD simulations. They found that both nonanionic and anionic surfactants showed promising results in terms of dispersant efficiency, but their performance can be affected by molecular structures and the hydrogen/carbon ratio of the asphaltene. Cao et al. [22] calculated the Hildebrand solubility of maltene and asphaltene by MD simulations. They have applied several structures with different features to examine the structural effect of asphaltene in n-heptane. Simulation results showed that the solubility parameter of asphaltene increased with the increasing number of benzene rings. Salah Yaseen [23] has explored the molecular interactions of asphaltene in water and n-heptane under different temperatures and pressures, chose three kinds of asphaltene structures from Athabasca oil sands, and adopted the OPLSAA force field for MD simulations. Results showed that compared with pressure, the contribution of temperature on interaction energies and hydrogen bonds was more prominent.

The aim of this study is to investigate the compatibility of asphaltene and other fractions in low-sulfur fuel oil by molecular dynamics simulation. We constructed the lowsulfur marine fuel model and conducted molecular dynamics simulations to analyze each component's solubility parameters, intermolecular energies, and radial distribution function (RDF) curves. By comparing the differences of solubility parameters, intermolecular energies, peak position, and peak value among different molecules, we can figure out each component's compatibility, thereby providing new ideas for marine low-sulfur fuel oil production and further theoretical research.

\section{Methodology}

2.1. Molecular Models. The composition of marine lowsulfur fuel oil is quite complex, and it is difficult to clarify the types and molecular structures of each fraction, so it is necessary to select models of several chemical compounds with representative characteristics [24].
As shown in Figure 1, the primary feedstock of marine low-sulfur oil is vacuum residue (VR) [25]. Therefore, to investigate the interactions between the molecules in lowsulfur fuel oil, representative VR components, i.e., saturate, aromatic, resin, and asphaltene (SARA), were selected as model compounds [26]. In addition, typically, a low-viscosity residue or light distillate oil is added to reduce the fuel oil viscosity and improve the combustion performance $[27,28]$. Therefore, hexadecane $(\mathrm{C} 16)$ was used as a representative compound for the light distillate. The SARA molecules chosen are based on existing studies of the components of VR [3,29], and molecular structures of the five compounds chosen to represent saturate, aromatic, and resin molecules are shown in Figure 2. The molecular models were built according to the protype developed by G\&D [30]. In addition to the molecular structures, the properties of each component are listed in Table 1.

Concerning the structure of asphaltene, many different models have been proposed $[3,4,19,31,32]$. There are two main types of asphaltene: island-type asphaltene has a single large aromatic core, and archipelago-type asphaltene has many small fused-ring structures connected by alkyl chains [33]. The island-type structure has a single fused-ring aromatic core and is relatively stable, whereas the archipelagotype structure has multiple fused-ring aromatic nuclei and is less stable [34]. In this study, we used the asphaltene model based on asphaltene extracted from Tahe oil field crude oil, which contains polar aromatic rings and a nonpolar paraffinic group and belongs to the island category.

Finally, molecular models of $n$-heptane and toluene were also built, and the solubility parameters obtained by molecular dynamics simulations were compared with the theoretical values to verify the accuracy of the simulation methods.

2.2. Force Field and Simulation Initialization. The molecular dynamics (MD) simulations were performed by Materials Studio 8.0, and COMPASS force field was used during the whole simulation process. As one of the most widely used force fields in the petroleum oil industry, COMPASS field includes bonded potential and nonbonded potential, and it is capable of accurately predicting structural, vibrational, and thermophysical properties for a broad range of organic and inorganic molecules, including asphaltene and diesel oil $[35,36]$. This force field is one of the best to be applied on heavy fuel oil and low-sulfur fuel oil models, as both of them are combined with amorphous, heavy organic molecules. The long-range electrostatic interaction was represented by Ewald interaction and the atom-based summation was applied by van der Waals interactions, Nose and Berendsen methods were utilized to control the temperature and pressure of the whole system, the cutoff radius was $1.25 \mathrm{~nm}$, and the time step was set $1 \mathrm{fs}$. The detailed simulation process is listed as follows:

(1) The five different molecules representing the components of low-sulfur oil, as well as n-heptane and toluene, were prepared in the visualizer module. 


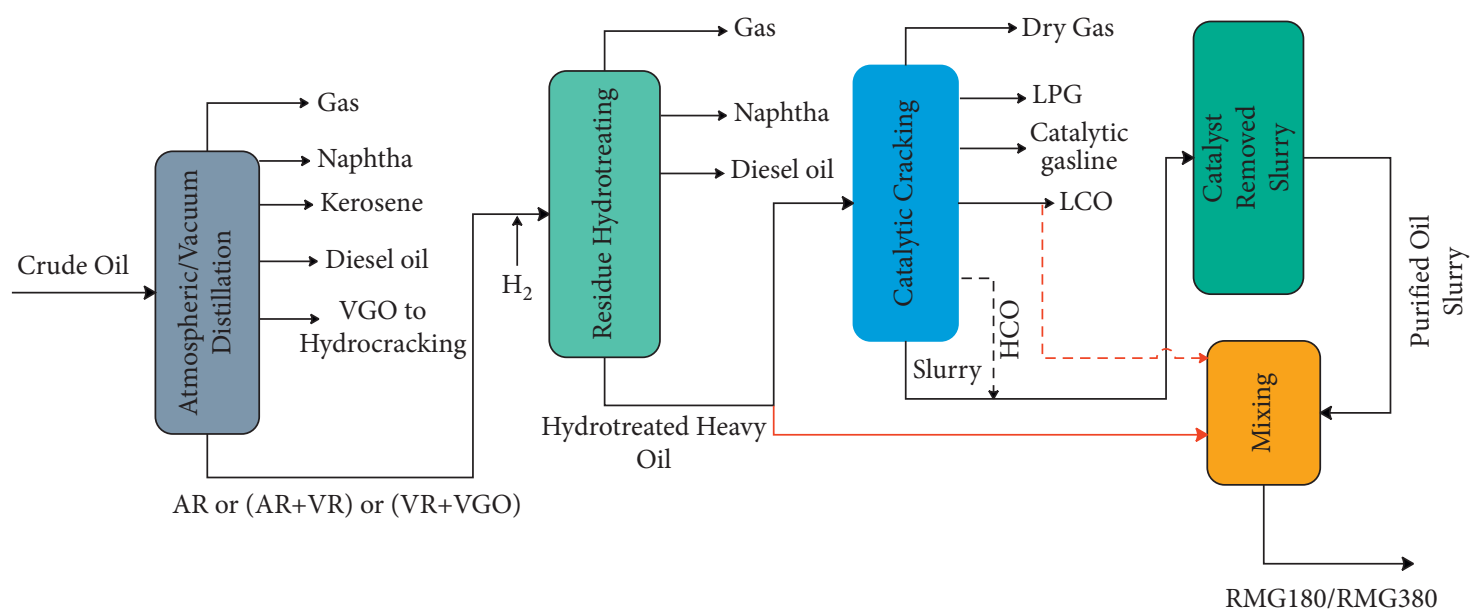

FIGURE 1: The flow chart of the marine low-sulfur fuel oil production process. AR: atmospheric residue; VR: vacuum residue; LCO: light circulate oil; HCO: heavy circulate oil; VGO: vacuum gas oil; and LPG: liquified petroleum gas.

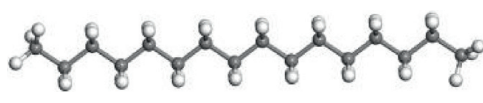

(a)

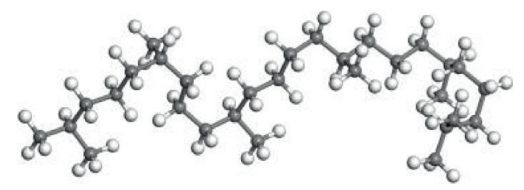

(b)

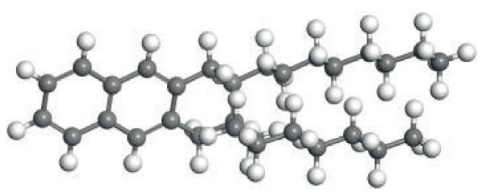

(c)

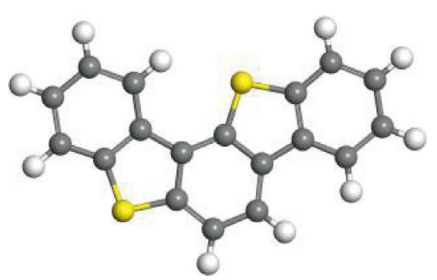

(d)

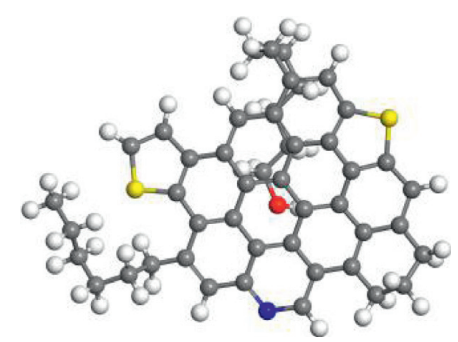

(e)

Figure 2: Molecular structure of each component in the low-sulfur fuel oil (carbon: grey, hydrogen: white, sulfur: yellow, and oxygen: red). (a) Hexadecane. (b) Saturate. (c) Aromatic. (d) Resin. (e) Asphaltene.

(2) We optimized the molecular model geometrically by the smart algorithm and gained the lowest energy configuration, then built an amorphous unit cell of 50 molecules with periodic boundary conditions by the amorphous cell module to ensure that the length of the unit cell was two times the cutoff radius. The initial density of the amorphous cell was set as $0.6 \mathrm{~g} /$ $\mathrm{cm}^{3}$ to ensure each molecule was distributed randomly [37].

(3) We performed geometric optimization to the cell again and optimized the model to perform 5 cycles of annealing at $300 \sim 500 \mathrm{~K}$ at the NPT ensemble; then, various types of conformations can be obtained after annealing, choosing the configurations with the lowest potential energy for the subsequent research.

(4) Under the temperature of $298 \mathrm{~K}$ and pressure of $0.1 \mathrm{MPa}$, the optimized models were subjected to molecular dynamics simulation of 300 ps at the NPT ensemble to shrink the volume and gain the density parameters. Then, the NVT ensemble was selected for 1000 ps dynamic simulation with a step size of $1.0 \mathrm{fs}$ and output 1 frame every 1000 steps to obtain the final equilibrium structure.

(5) After completing the dynamic simulation, the cohesive energy density (CED) function in the Forcite module was chosen to calculate the solubility parameters $(\delta)$ of each component.

(6) We constructed the amorphous unit cell with a mixture of two different molecules, filled 25 of each kind of molecules in the cell, repeated steps 2-4, and calculated the interaction energy of the mixed molecules through the script, and the average interaction energies of the last 20 frames were recorded.

For each system, the MD simulations were repeated three times independently to obtain the average value for further analysis. 
TABle 1: Diagrammatic sketches and properties of each component in the low-sulfur fuel oil.

\begin{tabular}{|c|c|c|c|c|c|c|}
\hline Name & Molecule model & Formula & Molecular weight & Atom number & Sulfur mass fraction & $\mathrm{H} / \mathrm{C}$ ratio \\
\hline Asphaltene & & $\mathrm{C}_{47} \mathrm{H}_{41} \mathrm{NOS}_{2}$ & 699.971 & 92 & $9.14 \%$ & 0.872 \\
\hline Resin & & $\mathrm{C}_{18} \mathrm{H}_{10} \mathrm{~S}_{2}$ & 290.398 & 30 & $22.038 \%$ & 0.556 \\
\hline Aromatic & & $\mathrm{C}_{30} \mathrm{H}_{46}$ & 406.698 & 76 & 0 & 1.533 \\
\hline Saturate & & $\mathrm{C}_{30} \mathrm{H}_{62}$ & 422.826 & 92 & 0 & 2.067 \\
\hline Hexadecane & & $\mathrm{C}_{16} \mathrm{H}_{34}$ & 226.448 & 50 & 0 & 2.125 \\
\hline
\end{tabular}

\section{Results and Discussion}

3.1. Morphology of Intermolecular Interactions. As illustrated in Figure 3, it can be seen that each component in the lowsulfur oil cell does not disperse uniformly, asphaltene molecules cannot exist independently, and they are aggregated with multiple molecules. The resin and asphaltene molecules tend to aggregate together as the resin molecules are always around the aggregates. Aromatic, saturate, and hexadecane molecules can exist independently, and they are distributed evenly in the entire system. Asphaltene molecules tend to form multiple aggregates, but they are not completely aggregated into a large compound; they are separated by the resin molecules and distributed in a continuous phase filled with aromatic and saturate molecules.

Figure 4 depicts snapshots of interaction morphology between asphaltene molecules and other fractions. Both face-to-face $(\pi-\pi)$ and face-to-edge $(\pi-\sigma)$ interactions exist in asphaltene-asphaltene dimers. As asphaltene molecules have a large aromatic core, they tend to aggregate and stack by the strong mutual interactions, while the presence of aliphatic side chains tends to hinder the direct $\pi-\pi$ interaction by a repulsive steric effect. Face-to-face $(\pi-\pi)$ interactions mainly contribute to the interactions between asphaltene and resin, as both of them have a high percentage of aromatic rings, while the resin molecule has a much shorter side chain, so resin molecules are more likely to combine with asphaltene molecules. Both aromatic rings and long aliphatic chains exist in aromatic molecules, and the repulsive steric effect formed by long alkyl chains overweigh the $\pi-\pi$ interaction imposed by a single aromatic ring with the asphaltene molecules. The alkyl chains in hexadecane and saturate molecules can only interact with side chains of asphaltene by weak van der Waals forces, and compared with the strong $\pi-\pi$ interaction, the van der Waals forces can be negligible, so asphaltene molecules tend to selfaggregate in an alkane solvent.
3.2. Solubility Parameters. There are many methods to evaluate the compatibility of different compounds. The solubility parameter is an important parameter to evaluate the magnitude of molecular interaction of organic molecules. It can work as a good indication of solubility for liquid organic compounds [38]. Hildebrand [39] proposed the concept of solubility parameter $\delta$ in the middle of the 20th century, which is defined as the square root of the cohesive energy density. It can characterize the strength of the force between the molecules of a substance. The solubility parameter is defined as follows [40]:

$$
\delta=\sqrt{\frac{E_{\mathrm{coh}}}{V}}=\sqrt{\mathrm{CED}},
$$

where $E_{\text {coh }}$ is the cohesive energy; $V$ is the molar volume; and $\mathrm{CED}$ is the cohesive energy density.

At present, there are two methods of obtaining the solubility parameters of liquid compounds: the experimental method and calculation method [41]. For conventional solvents, it can be obtained by a practical approach or by querying relevant literature data. However, for compounds with complex structures such as resin and asphaltene, their solubility parameters can vary with the different structures, so it is not easy to gain by the experimental method. On the other hand, by using molecular simulation technology, we can gain the solubility parameter of each compound under different conditions and find out the most suitable one for mixing to reduce the risk of incompatibility.

The solubility parameter introduced by Hildebrand is only suitable for the nonpolar compounds. In the model of low-sulfur fuel oil, both asphaltene and resin molecules contain polar atoms, so this parameter does not suit the model quite well. Hansen modified the theory by introducing the three-dimension parameters: nonpolar, dipolar, and hydrogen bonding, and it can be expressed by the following equation:

$$
\delta^{2}=\delta d^{2}+\delta p^{2}+\delta h^{2}
$$




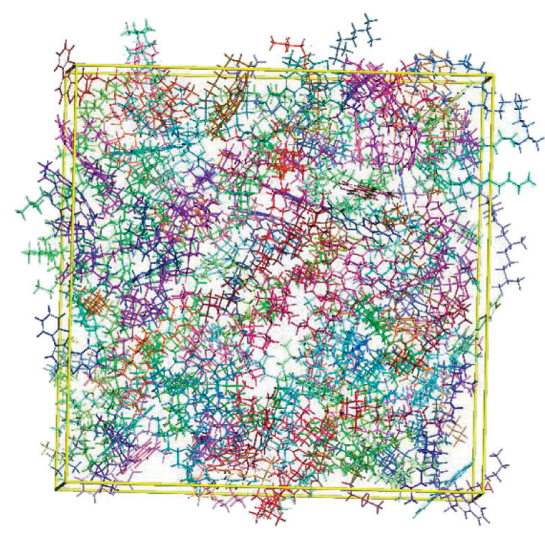

(a)

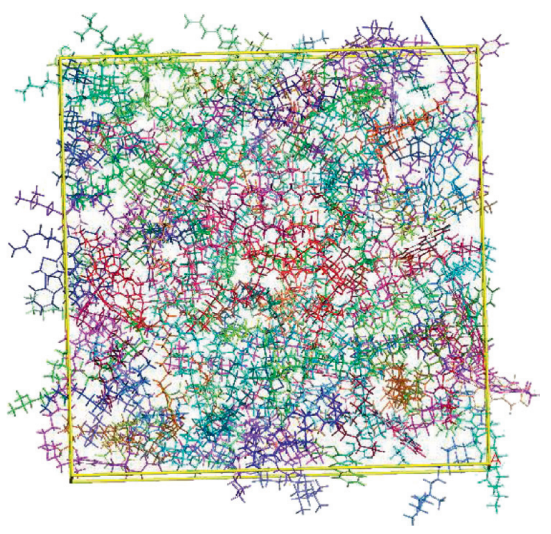

(b)

FIgURE 3: Illustration of low-sulfur fuel oil molecular structures at $298 \mathrm{~K}$ (asphaltene: green, resin: orange, aromatic: blue, saturate: yellow, and hexadecane: pink). (a) Initial configuration. (b) Equilibrium configuration after 1 ns simulation.

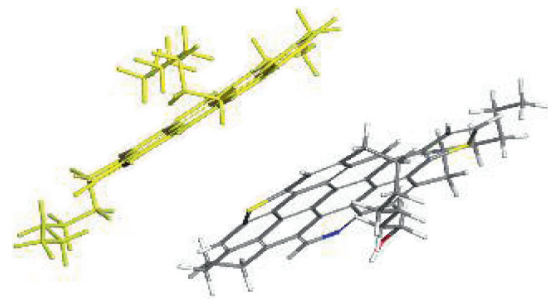

asphaltene-asphaltene $(\pi-\pi)$

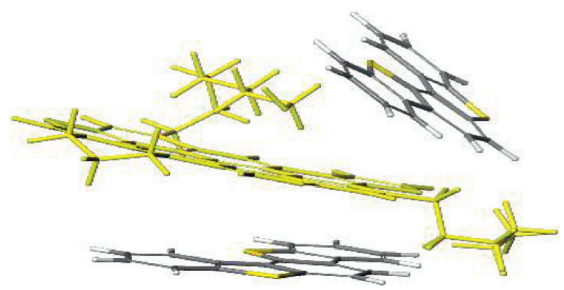

asphaltene-rein

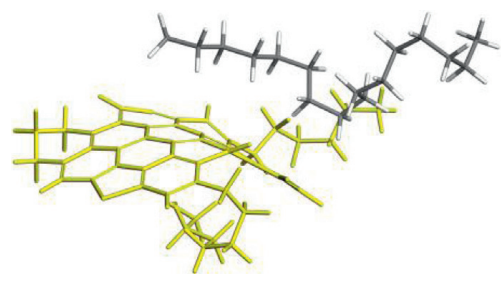

asphaltene-hexadecane

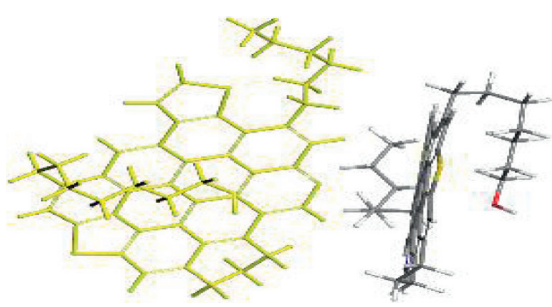

asphaltene-asphaltene $(\pi-\sigma)$

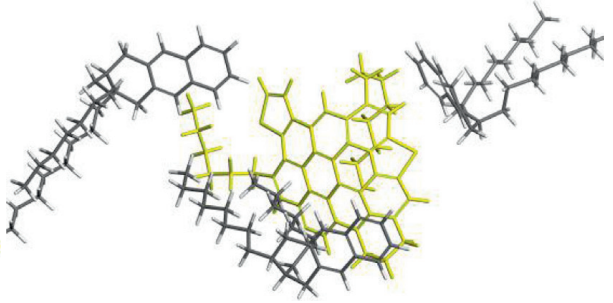

asphaltene-aromatic

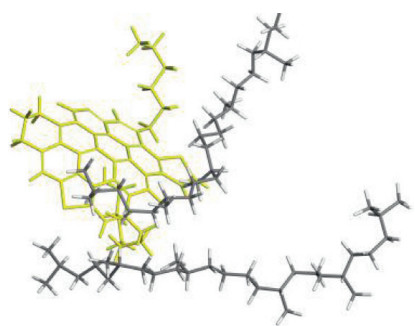

asphaltene-saturate

FIgURE 4: Morphology of asphaltene molecules with other fractions at $298 \mathrm{~K}$.

where $\Delta d, \delta p$, and $\delta h$ represent the dispersive, electrostaticpolar, and hydrogen force, respectively.

According to the theory of "similarity and intermiscibility" (like dissolves like), if two different kinds of compounds can be completely miscible with each other, it means that all their solubility parameters should be similar [42]. It is widely accepted that two kinds of liquid tend to be mutually miscible on the condition of $|\Delta \delta|<1.3-2.1$ with nonpolar groups or hydrogen bonds between molecules. Since the hydrogen bonding interaction is not included in the COMPASS force field, it is incorporated into other nonbonding interaction terms, so the calculated solubility parameters are expressed by $\delta_{\mathrm{vdw}}$ and $\delta_{\text {elec }}$, which represent the solubility parameter generated by van der Waals force and electrostatic force, respectively [43], where $\delta^{2}=\delta_{\mathrm{vdw}}{ }^{2}+\delta_{\text {ele }}{ }^{2}$.

From Table 2, we can see that the difference between the calculated solubility parameters and experimental values of $\mathrm{n}$-heptane and toluene under the conditions of $298 \mathrm{~K}$ and 
TABLE 2: Calculated and experimental solubility parameters at $298 \mathrm{~K}$.

\begin{tabular}{lccc}
\hline Name & $\begin{array}{c}\text { Calculated } \\
\text { value } \\
\delta\left(\mathrm{J} / \mathrm{cm}^{-3}\right)^{0.5}\end{array}$ & $\begin{array}{c}\text { Experimental } \\
\text { value } \\
\delta\left(\mathrm{J} / \mathrm{cm}^{-3}\right)^{0.5}\end{array}$ & $\begin{array}{c}\text { Error range } \\
(\%)\end{array}$ \\
\hline$n-$ & 15.327 & 15.3 & 0.17 \\
heptane & 18.248 & 18.0 & 1.3 \\
Toluene & &
\end{tabular}

$0.1 \mathrm{MPa}$ is quite small, and the error range is less than $1 \%$. Thus, the good accordance between the simulated result and the experiment value can prove that accuracy of the solubility parameters gained by molecular dynamics simulation is very high.

From Table 3, we can find that the densities of hexadecane and saturate are similar, but both are much lower than those of the resin and asphaltene. The density of aromatic lies in the middle of this range, whereas those of the resin and asphaltene are two times higher than those of the hexadecane and saturate models. According to previous research, if the difference in density of two liquid components exceeds a certain value, a mixture will be unstable. Furthermore, the density of a chemical compound also has a close link with its solubility parameter [44]. As shown in Table 3, the densities of aromatic, resin, and asphaltene increase in that order, and this can be related to the presence of many aromatic rings and few side branches. This results in a smaller molecular volume and a higher cohesive energy, which means a molecule is more likely to have stronger selfinteractions and, thus, a high solubility parameter [42].

From the perspective of the solubility parameter, it can be seen that resin gets the highest value, asphaltene has a similar value with resin, while both saturate and hexadecane molecules are much lower, and the hexadecane is slightly higher than saturate. The primary contribution to solubility parameters for all components is van der Waals interaction, while the intensity of electrostatic interaction is relatively low. Since there are no polar atoms in hexadecane and saturate molecules, hydrogen bond and electrostatic interaction could exist, so their cohesive energy densities are relatively low, and the solubility parameters are also lower than those of other components [45]. Hexadecane is a kind of straight-linked alkane without any branches, but branches on the saturate molecules can form a steric hindrance, affecting the intermolecular forces, resulting in a low cohesive energy density. Although the molecular structure of aromatic also does not contain any polar atoms, the aromatic ring structure can form a solid $\pi-\pi$ interaction, so the strength of the intermolecular interaction is proportional to the number of the aromatic rings.

The solubility parameter difference between resin and asphaltene is 0.586 , and the values related to composition items $\delta_{\text {elec }}$ and $\delta_{\mathrm{vdw}}$ are relatively similar, which means that compatibility between resin and asphaltene is high. Both resin and asphaltene molecules contain a large number of aromatic rings and polar atoms. Due to the high proportion of aromatic rings in resin and asphaltene, their cohesive energy density is much higher than that of aromatic under
TABLE 3: Solubility parameters and densities of each component in low-sulfur fuel oil at $298 \mathrm{~K}$.

\begin{tabular}{lcccc}
\hline Name & $\begin{array}{c}\delta\left(\mathrm{J} \cdot \mathrm{cm}^{-3}\right) \\
0.5\end{array}$ & $\begin{array}{c}\delta_{\mathrm{vdw}}\left(\mathrm{J} \cdot \mathrm{cm}^{-3}\right) \\
0.5\end{array}$ & $\begin{array}{c}\delta_{\text {elec }}\left(\mathrm{J} \cdot \mathrm{cm}^{-3}\right) \\
0.5\end{array}$ & $\begin{array}{c}\rho \\
\left(\mathrm{g} \cdot \mathrm{cm}^{-3}\right)\end{array}$ \\
\hline Hexadecane & 16.592 & 16.231 & 0.514 & 0.775 \\
Saturate & 16.165 & 15.778 & 0.491 & 0.818 \\
Aromatic & 18.108 & 17.784 & 2.237 & 0.921 \\
Resin & 22.908 & 22.384 & 0.394 & 1.317 \\
Asphaltene & 22.322 & 21.693 & 0.785 & 1.219 \\
\hline
\end{tabular}

the influence of $\pi$ - $\pi$ interaction. The ratio of aromatic rings in resin molecules is lower than that in asphaltene, but its solubility parameter is slightly higher than that of asphaltene. This can be explained by that there are more alkyl side chains in asphaltene molecules, which can intensify the steric hindrance effect and block the $\pi-\pi$ interaction between aromatic rings. Furthermore, asphaltene molecules contain many negatively charged heteroatoms such as $S, N$, and $O$, which can form a strong hydrogen bond with the positively charged hydrogen atoms, so its electrostatic interaction strength is greater than that of resin molecules [46]. Even though the electrostatic effect of asphaltene is more substantial than that of resin, the electrostatic effect is still not strong enough to offset the hindrance of the side chain to the $\pi-\pi$ interaction, so the cohesive energy density of resin is a little higher than that of asphaltene.

3.3. Interaction Energy. The interaction energy $\left(E_{\text {inter }}\right)$ is a parameter that describes the strength of the interaction between an individual molecule in a multimolecular system, and it can also predict the compatibility between two components [47]. If the interaction energy is a positive value, it means that the interaction between the two components is mainly for mutual repulsion, which means they are incompatible with each other. On the other side, a negative $E_{\text {inter }}$ value represents good compatibility; the larger the absolute value is, the more vigorous the mutual interaction or binding strength is and the more stable the solution. It can be expressed as follows [41]:

$$
E_{\text {inter }}=E_{\text {total }}-E_{A-A}-E_{B-B},
$$

where $E_{\text {inter }}$ represents the interaction energy between two different molecules, $E_{\text {total }}$ represents the total energy of two molecules, and $E_{A-A}$ and $E_{B-B}$ represent the total energy of the same molecules, respectively.

The strength of the molecule interaction mainly depends on its structural characteristics. Intermolecular interactions are mainly contributed by van der Waals and Coulombic interactions [48]. The strength of van der Waals interaction is closely related to the surface area and its electronic polarizability. Coulombic interaction is affected by the polarity and the heteroatoms $(O, N$, and $S)$ [49].

As shown in Table 4, the interaction energy between asphaltene and resin is much higher than the mutual interactions of the same molecules, which means that asphaltene molecules are more likely to combine with resin molecules. In addition, the interaction energy between resin, 
TABLE 4: Interaction energies of different pairs at $298 \mathrm{~K}$.

\begin{tabular}{lc}
\hline Molecules & Interaction energy $\left(\mathrm{kJ} / \cdot \mathrm{mol}^{-1}\right)$ \\
\hline Asphaltene-asphaltene & -1370.26 \\
Asphaltene-resin & -1797.04 \\
Asphaltene-aromatic & -1218.74 \\
Asphaltene-saturate & -838.53 \\
Asphaltene-hexadecane & -685.14 \\
Resin-resin & -1138.31 \\
Resin-aromatic & -2548.61 \\
Resin-saturate & -529.24 \\
Resin-hexadecane & -336.19 \\
Aromatic-aromatic & -1469.36 \\
Aromatic-saturate & -1811.14 \\
Aromatic-hexadecane & -1956.46 \\
Saturate-saturate & -1590.72 \\
Saturate-hexadecane & -597.59 \\
Hexadecane-hexadecane & -961.38 \\
\hline
\end{tabular}

aromatic, saturate, and hexadecane molecules with asphaltene molecules decreases, respectively. The interaction energy between aromatic and resin molecules is relatively high, mainly because the aromatic ring of the aromatic component can form a strong $\pi-\pi$ interaction, which means that aromatic can disperse the resin aggregates well into the solution system. The interaction energies of asphaltene with saturate and the hexadecane molecules are lower than those of the asphaltene-asphaltene interaction, which means that compared with a linear alkane compound, asphaltene prefers interacting with the same kind of molecules, so it is difficult to dissolve it in an alkane solution. Furthermore, solutions with a high concentration of alkane fraction will dilute the ratio of the resin and aromatic molecules around the asphaltene, which can lead to asphaltene aggregation or precipitation. The interaction energy of aromatic with saturate and hexadecane molecules is higher than that of the aromatic-aromatic interaction, indicating that the aromatic molecules are more likely to combine with saturate and hexadecane rather than the same kind of molecules. This can be attributed to the alkyl chain structure in an aromatic molecule that interacts with saturate and hexadecane.

The interaction of the low-sulfur fuel oil system is entirely consistent with the microstructure of each component. For asphaltene molecules, they tend to dissolve in solutions in the presence of resin and aromatic, and the increasing percentage of saturate or hexadecane in the solution can inhibit the asphaltene dissolution.

3.4. Radial Distribution Function (RDF). The radial distribution function $g(r)$ means the probability of occurrence of one particle at a distance $r$ from the other particle, which is a function of distance from a reference particle [50-52]. The calculation formula can be expressed as the follows:

$$
g(r)=\frac{\mathrm{d} N}{\rho 4 \pi r^{2} \mathrm{~d} r},
$$

where $r$ is the distance between particles, $N$ is the number of particles, and $\rho$ is the average density of the whole system.
For an amorphous compound, the $g(r)$ value is equal to 1 when the distance $r$ is considerably large. However, several peaks can appear near the origin position, which means that the probability of appearance for the other kind of particle at these locations is much higher than that at the other positions. Therefore, the RDF curve can characterize the average distance between molecules in the molecular cell, and it can be also be utilized to analyze the agglomeration condition of the chemical compound in different solvents.

When the peak value of the RDF curve at a distance is more prominent than that of the other distances, the agglomeration occurs at this position. As low-sulfur fuel oil is a kind of amorphous mixture, the difference between RDF curves can be used to describe the agglomeration behavior of asphaltene. In this study, the most vital characteristics of the RDF curves are the first peak position and peak value, which concern the agglomeration pattern and aggregation tendency of each component.

In this work, distances between different molecules were calculated based on the center of mass (COM) to judge the aggregation behavior of asphaltene at a molecular level. The RDF curves of asphaltene-asphaltene, asphaltene-resin, asphaltene-aromatic, asphaltene-saturate, and asphaltenehexadecane pairs in heavy fuel and low-sulfur fuel oil are shown in Figure 4. Trajectories obtained from the last $200 \mathrm{ps}$ of MD simulations under the NVT ensemble were selected for the RDF analysis.

Figure 5 demonstrates changes of RDF curves between asphaltene and other components before and after adding the light distillate oil, which can be used to figure out the influence of light components on other fractions in the heavy fuel oil. According to previous research, the maximum hydrogen bonds length is $2.5 \AA$, as no peak is found at a distance lower than $2.5 \AA$ in heavy fuel oil and low-sulfur fuel oil RDF curves, so hydrogen bond does not exist in both models [53].

For the heavy fuel oil model, the RDF curve of asphaltene-asphaltene pairs presented a relatively high peak value compared to other oil fractions, indicating a strong tendency of self-aggregation. Furthermore, the two peak positions of asphaltene-asphaltene pairs presented at $5.2 \AA$ and $7.8 \AA$, and these peak distances are considerably larger than the average $\pi-\pi$ interaction distance, indicating that asphaltene molecules tend to aggregate in the form of faceto-edge and offset geometry. The number of aromatic rings in asphaltene molecules is much higher than other factions generating a strong $\pi-\pi$ interaction and reducing the RDF peak distance, but the presence of alkyl chains can form a repulsive steric effect which hinders the mutual interaction and enlarges the RDF peak distance. On the other hand, a weak aggregation tendency was observed for asphalteneresin pairs, with a low peak value. From the peak position, we can conclude that there are two kinds of aggregating structures in asphaltene-resin pairs; the first peak at $3.5 \AA$ corresponds to the face-to-face structure, while the second peak at 5.2 corresponds to the face-to-edge structure. Though the number of aromatic rings in resin molecule is much less than that in asphaltene, there are no alkyl chains also, so the resin molecules can form a strong interaction 


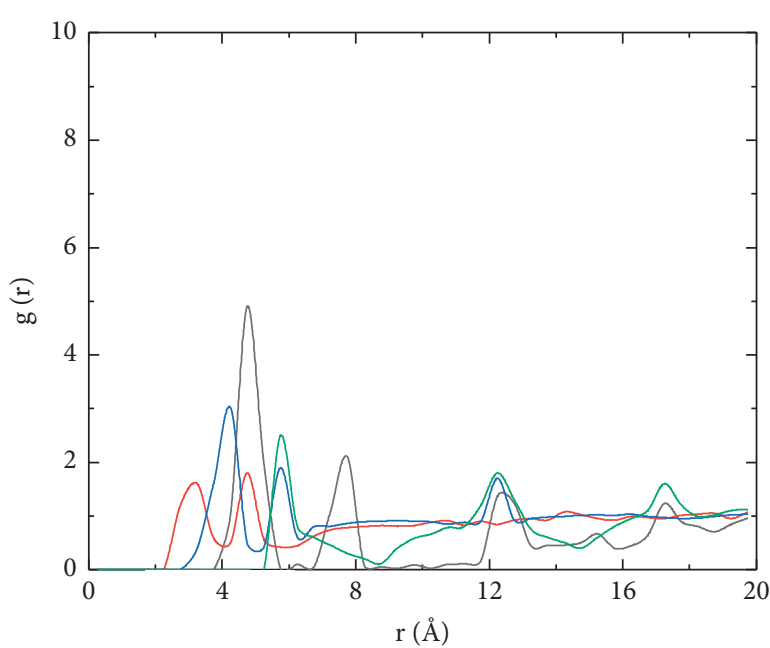

- Asphaltene-Asphaltene — Asphaltene-Aromatic
Asphaltene-Resin $\quad$ Asphaltene-Saturate

(a)

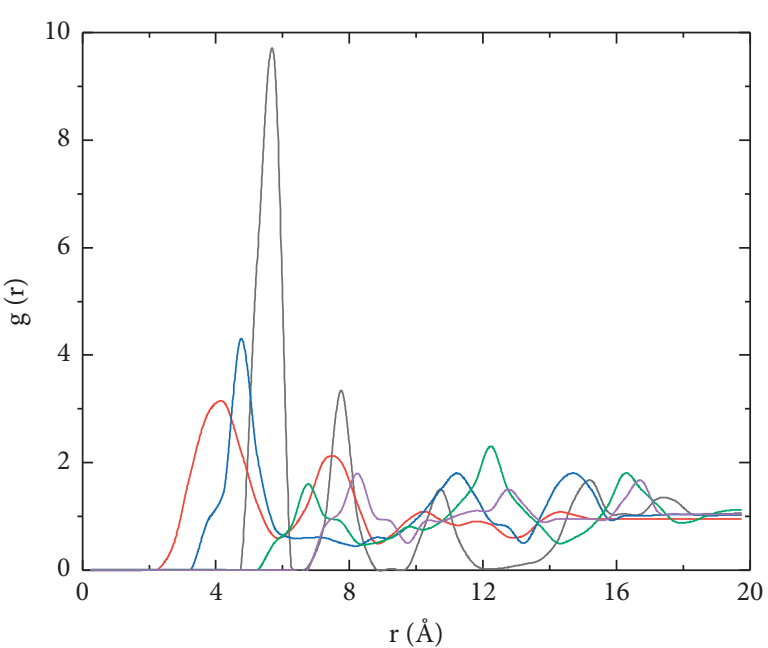

Asphaltene-Asphaltene - Asphaltene-Saturate
Asphaltene-Resin $\begin{aligned} & \text { Asphaltene-C16 } \\ & \text { Asphaltene-Aromatic }\end{aligned}$

(b)

FIGURE 5: RDF curves of asphaltene with other components. (a) Heavy fuel oil. (b) Low-sulfur fuel oil.

with asphaltene and narrow the RDF peak distance. Due to the presence of alkyl chains in both aromatic and saturate molecules, the peak value of asphaltene-aromatic and asphaltene-saturate pairs is relatively low, and the asphaltene molecules are less likely to interact with them in this model [54].

After blending with light distillate oil, the molecular structure of heavy fuel oil changed. The first peak position of asphaltene-asphaltene pairs moved right from 5.2 to $5.8 \AA$, which means asphaltene molecules still aggregated in the form of face-to-edge and offset geometry. The peak value $g(r)$ of asphaltene-asphaltene pairs increased from 4.9 to 9.8, which is two times higher than that before, indicating a stronger self-aggregation occurs in the low-sulfur fuel oil model. The strong aggregation behavior of asphaltene in low-sulfur fuel oil can be attributed to the presence of aromatic core and heteroatoms in asphaltene molecules [55]. The first peak position of asphaltene-resin and asphaltenearomatic pairs in the low-sulfur fuel oil model is closer to the original position, and this can be explained that both resin and aromatic molecules are smaller and contain aromatic rings, so the interactions of asphaltene with resin and aromatic molecules are stronger than those of other fractions; in other words, both resin and aromatic molecules can serve as an asphaltene dispersant medium to inhibit asphaltene self-aggregation. The peak values in RDF curves of asphaltene-saturate and asphaltene-hexadecane pairs are much lower compared with other fractions, which means that there are quite few saturate and hexadecane molecules around the asphaltene; in other words, saturate and light distillate oil molecules are highly incompatible with the asphaltene and the presence of saturate and hexadecane molecule can accelerate the asphaltene aggregation process. The weak interaction between light distillate oil and asphaltene could be attributed to the nonpolar properties of light distillate oil molecules and also their small overall mole fraction in the whole system. In summary, the influence of light distillate oil on the first peak position is significant, indicating that it is highly incompatible with the asphaltene component in heavy fuel oil.

\section{Conclusions}

The effect of adding light distillate oil into heavy fuel oil to produce low-sulfur fuel oil was studied by MD simulation. Based on the simulation results of the solubility parameters, interaction energies, and radical distribution function curves of each component, we draw the following conclusions:

(1) The structural characteristics of various types of molecules in marine low-sulfur oil determine the strength of interaction between different molecules. Specifically, more aromatic rings and fewer alkyl side chains result in stronger interactions, as well as greater cohesive energy densities and solubility parameters.

(2) The interaction energy of asphaltene-saturate and asphaltene-hexadecane is lower than that of asphaltene-asphaltene. Therefore, asphaltene is less likely to combine with alkane molecules, making its dissolution in an alkane solution challenging. On the other hand, the solubility parameter of resin is closest to that of asphaltene, suggesting that it is the main solvent for dissolving asphaltene.

(3) Adding the light distillate oil into heavy fuel oil, the mass ratio of each component changed. Thus, the asphaltene was more likely to self-aggregate, as shown by the dramatic increase in the peak value, although the peak position was unchanged, which 
indicates the pattern of asphaltene interaction is still unchanged.

\section{Data Availability}

The data used to support the findings of this study are included within the supplementary information files.

\section{Conflicts of Interest}

The authors declare no conflicts of interest.

\section{Supplementary Materials}

Supplementary material is supplementary figures regarding the molecular modeling study. Figure S1: RDF parameters of asphaltene with other molecules in low-sulfur fuel oil. S2: RDF parameters of asphaltene with other molecules in heavy fuel oil. (Supplementary Materials)

\section{References}

[1] A. G. Abdul Jameel, A. Alkhateeb, and S. Telalović, "Environmental challenges and opportunities in marine engine heavy fuel oil combustion," in Proceedings of the Fourth International Conference in Ocean Engineering, Singapore, November 2019.

[2] T. Chu Van, J. Ramirez, T. Rainey, Z. Ristovski, and R. J. Brown, "Global impacts of recent IMO regulations on marine fuel oil refining processes and ship emissions," Transportation Research Part D: Transport and Environment, vol. 70, pp. 123-134, 2019.

[3] A. M. Elbaz, A. Gani, N. Hourani, A.-H. Emwas, S. M. Sarathy, and W. L. Roberts, "TG/DTG, FT-ICR mass spectrometry, and NMR spectroscopy study of heavy fuel oil," Energy \& Fuels, vol. 29, no. 12, pp. 7825-7835, 2015.

[4] A. G. Abdul Jameel, A. M. Elbaz, and A. Emwas, "Calculation of average molecular parameters, functional groups, and a surrogate molecule for heavy fuel oils using $1 \mathrm{~h}$ and $13 \mathrm{c}$ nuclear magnetic resonance spectroscopy," Energy \& Fuels, vol. 30, no. 5, pp. 3894-3905, 2015.

[5] P. Yi, T. Li, Y. Wei, and X. Zhou, "Experimental and numerical investigation of low sulfur heavy fuel oil spray characteristics under high temperature and pressure conditions," Fuel, vol. 286, Article ID 119327, 2021.

[6] A. Halff, L. Younes, and T. Boersma, "The likely implications of the new IMO standards on the shipping industry," Energy Policy, vol. 126, pp. 277-286, 2019.

[7] Y.-S. Choi and T.-W. Lim, "Numerical simulation and validation in scrubber wash water discharge from ships," Journal of Marine Science and Engineering, vol. 8, no. 4, p. 272, 2020.

[8] R. D. I. S. Stratiev, "Can we manage the process of asphaltene precipitation during the production of IMO 2020 fuel oil," Erdol Erdgas Kohle, vol. 12, pp. 34-41, 2020.

[9] S. Aramkitphotha, H. Tanatavikorn, C. Yenyuak, and T. Vitidsant, "Low sulfur fuel oil from blends of microalgae pyrolysis oil and used lubricating oil: properties and economic evaluation," Sustainable Energy Technologies and Assessments, vol. 31, pp. 339-346, 2019.

[10] R. Guzmán, J. Ancheyta, F. Trejo, and S. Rodríguez, "Methods for determining asphaltene stability in crude oils," Fuel, vol. 188, pp. 530-543, 2017.
[11] D. Simionesie, G. O’Callaghan, R. Laurent, J. A. Preece, R. Evans, and Z. J. Zhang, "Combined experimental and computational study of polyaromatic hydrocarbon aggregation: isolating the effect of attached functional groups," Industrial \& Engineering Chemistry Research, vol. 58, no. 45, pp. 20505-20515, 2019.

[12] A. Tirjoo, B. Bayati, H. Rezaei, and M. Rahmati, "Molecular dynamics simulations of asphaltene aggregation under different conditions," Journal of Petroleum Science and Engineering, vol. 177, pp. 392-402, 2019.

[13] H. Santos Silva, A. Alfarra, G. Vallverdu, D. Bégué, B. Bouyssiere, and I. Baraille, "Asphaltene aggregation studied by molecular dynamics simulations: role of the molecular architecture and solvents on the supramolecular or colloidal behavior," Petroleum Science, vol. 16, no. 3, pp. 669-684, 2019.

[14] F. Gao, Z. Xu, G. Liu, and S. Yuan, "Molecular dynamics simulation: the behavior of asphaltene in crude oil and at the oil/water interface," Energy \& Fuels, vol. 28, no. 12, pp. 7368-7376, 2014.

[15] D. Ji, G. Liu, X. Zhang, C. Zhang, and S. Yuan, "Molecular dynamics study on the adsorption of heavy oil drops on a silica surface with different hydrophobicity," Energy \& Fuels, vol. 34, no. 6, pp. 7019-7028, 2020.

[16] Y. Gan, Q. Cheng, Z. Wang, J. Yang, W. Sun, and Y. Liu, "Molecular dynamics simulation of the microscopic mechanisms of the dissolution, diffusion and aggregation processes for waxy crystals in crude oil mixtures," Journal of Petroleum Science and Engineering, vol. 179, pp. 56-69, 2019.

[17] J. Nian, L. Chen, Z. Guo, and W. Liu, "Computational investigation of the lubrication behaviors of dioxides and disulfides of molybdenum and tungsten in vacuum," Friction, vol. 5, no. 1, pp. 23-31, 2017.

[18] M. Ahmadi, Q. Hou, Y. Wang, and Z. Chen, "Interfacial and molecular interactions between fractions of heavy oil and surfactants in porous media: comprehensive review," Advances in Colloid and Interface Science, vol. 283, Article ID $102242,2020$.

[19] E. Rogel, "Simulation of interactions in asphaltene aggregates," Energy \& Fuels, vol. 14, no. 3, pp. 566-574, 2000.

[20] B. B. H. R. Amin Tirjoo and M. Rahmati, "Molecular dynamics simulation of the effect of ions in water on the asphaltene aggregation," Journal of Molecular Liquids, vol. 277, pp. 40-48, 2018.

[21] G. A. M. Mohammed and H. Khalaf, "A new insight into asphaltenes aggregation onset at molecular level in crude oil (an MD simulation study)," Journal of Petroleum Science and Engineering, vol. 162, pp. 244-250, 2017.

[22] T. Cao, C. Wang, Y. Xiong et al., "Self-assembly and solubility properties of polyaromatic compounds studied by molecular dynamics simulation," Fuel, vol. 277, Article ID 118060, 2020.

[23] G. A. M. Salah Yaseen, "Molecular dynamics studies of interaction between asphaltenes and solvents," Journal of Petroleum Science and Engineering, vol. 156, pp. 118-124, 2017.

[24] N. K. Kondrasheva, D. O. Kondrashev, V. A. Rudko, and A. A. Shaidulina, "Effect of hydrocarbon composition on quality and operating characteristics of middle distillate fractions and low-viscosity marine fuels," Chemistry and Technology of Fuels and Oils, vol. 53, no. 2, pp. 163-172, 2017.

[25] V. Garaniya, D. Mcwilliam, L. Goldsworthy, and M. Ghiji, "Extensive chemical characterization of a heavy fuel oil," Fuel, vol. 227, pp. 67-78, 2018.

[26] S. Ashoori, M. Sharifi, M. Masoumi, and M. Mohammad Salehi, "The relationship between SARA fractions and crude 
oil stability," Egyptian Journal of Petroleum, vol. 26, no. 1, pp. 209-213, 2017.

[27] U. Käfer, T. Gröger, C. J. Rohbogner et al., "Detailed chemical characterization of bunker fuels by high-resolution time-offlight mass spectrometry hyphenated to GC $\times$ GC and thermal analysis," Energy \& Fuels, vol. 33, no. 11, pp. 10745-10755, 2019.

[28] G. Borówka, K. Bytnar, and M. Krzak, "Physicochemical properties of fuel blends composed of heavy fuel oil and tirederived pyrolytic oils," Journal of Energy Resources Technology, vol. 141, no. 4, 2019.

[29] A. G. Abdul Jameel, A. Khateeb, A. M. Elbaz et al., "Characterization of deasphalted heavy fuel oil using APPI (+) FTICR mass spectrometry and NMR spectroscopy," Fuel, vol. 253, pp. 950-963, 2019.

[30] D. D. Li and M. L. Greenfield, "Chemical compositions of improved model asphalt systems for molecular simulations," Fuel, vol. 115, pp. 347-356, 2014.

[31] J. J. Adams, "Asphaltene adsorption, a literature review," Energy \& Fuels, vol. 28, no. 5, pp. 2831-2856, 2014.

[32] I. A. Wiehe and K. S. Liang, "Asphaltenes, resins, and other petroleum macromolecules," Fluid Phase Equilibria, vol. 117, no. 1, pp. 201-210, 1996.

[33] S. Fakher, M. Ahdaya, M. Elturki, and A. Imqam, "Critical review of asphaltene properties and factors impacting its stability in crude oil," Journal of Petroleum Exploration and Production Technology, vol. 10, no. 3, pp. 1183-1200, 2020.

[34] P. Qiao, PHD, University of Alberta, 2019.

[35] H. Sun, "COMPASS: an ab initio force-field optimized for condensed-phase applications overview with details on alkane and benzene compounds," Journal of Physical Chemistry B, vol. 102, no. 38, pp. 7338-7364, 1998.

[36] H. Sun, P. Ren, and J. R. Fried, "The COMPASS force field: parameterization and validation for phosphazenes," Computational and Theoretical Polymer Science, vol. 8, no. 1, pp. 229-246, 1998.

[37] M. Ahmadi and Z. Chen, "Molecular interactions between asphaltene and surfactants in a hydrocarbon solvent: application to asphaltene dispersion," Symmetry, vol. 12, no. 11, p. $1767,2020$.

[38] K. Sharma, T. H. Pedersen, S. S. Toor, Y. Schuurman, and L. A. Rosendahl, "Detailed investigation of compatibility of hydrothermal liquefaction derived biocrude oil with fossil fuel for corefining to drop-in biofuels through structural and compositional analysis," ACS Sustainable Chemistry \& Engineering, vol. 8, no. 22, pp. 8111-8123, 2020.

[39] E. Rogel, "Studies on asphaltene aggregation via computational chemistry," Colloids and Surfaces A: Physicochemical and Engineering Aspects, vol. 104, no. 1, pp. 85-93, 1995.

[40] E. Rogel, C. Ovalles, K. D. Bake et al., "Asphaltene densities and solubility parameter distributions: impact on asphaltene gradients," Energy \& Fuels, vol. 30, no. 11, pp. 9132-9140, 2016.

[41] Y. Guo, J. Liu, and Y. Lu, “A combined molecular dynamics simulation and experimental method to study the compatibility between elastomers and resins," RSC Advances, vol. 8, no. 26, pp. 1441-14413, 2018.

[42] F. Guo, J. Zhang, J. Pei, W. Ma, Z. Hu, and Y. Guan, "Evaluation of the compatibility between rubber and asphalt based on molecular dynamics simulation," Frontiers of Structural and Civil Engineering, vol. 14, no. 2, pp. 435-445, 2020.

[43] S. Amjad-Iranagh, M. Rahmati, M. Haghi, M. Hoseinzadeh, and H. Modarress, "Asphaltene solubility in common solvents: a molecular dynamics simulation study," The Canadian Journal of Chemical Engineering, vol. 93, no. 12, pp. 2222-2232, 2015.

[44] S. R. Panuganti, F. M. Vargas, and W. G. Chapman, "Property scaling relations for nonpolar hydrocarbons," Industrial \& Engineering Chemistry Research, vol. 52, no. 23, pp. 80098020, 2013.

[45] G.-w. Lu, Y.-f. Li, H. Song, Y.-h. Yu, and C.-l. Wang, "Micromechanism of petroleum asphaltene aggregation," Petroleum Exploration and Development, vol. 35, no. 1, pp. 67-72, 2008.

[46] R. Skartlien, S. Simon, and J. Sjöblom, "DPD molecular simulations of asphaltene adsorption on hydrophilic substrates: effects of polar groups and solubility," Journal of Dispersion Science and Technology, vol. 37, no. 6, pp. 866-883, 2016.

[47] Y. Luoa, W. Runguo, and Z. Suhe, "Experimental study and molecular dynamics simulation of dynamic properties and interfacial bonding characteristics of graphene/solution-polymerized styrene-butadiene rubber composites," RSC Advances, vol. 6, no. 63, pp. 58077-58087, 2016.

[48] M. Ahmadi and Z. Chen, "Comprehensive molecular scale modeling of anionic surfactant-asphaltene interactions," Fuel, vol. 288, Article ID 119729, 2021.

[49] X. Zhu, D. Chen, and G. Wu, "Molecular dynamic simulation of asphaltene co-aggregation with humic acid during oil spill," Chemosphere, vol. 138, pp. 412-421, 2015.

[50] F. Guo, J. Zhang, J. Pei, B. Zhou, A. C. Falchetto, and Z. Hu, "Investigating the interaction behavior between asphalt binder and rubber in rubber asphalt by molecular dynamics simulation," Construction and Building Materials, vol. 252, Article ID 118956, 2020.

[51] W. Xu, X. Qiu, S. Xiao, G. Hu, F. Wang, and J. Yuan, "Molecular dynamic investigations on the adhesion behaviors of asphalt mastic-aggregate interface," Materials, vol. 13, no. 22, p. 5061, 2020.

[52] Y. Ding, M. Deng, X. Cao, M. Yu, and B. Tang, "Investigation of mixing effect and molecular aggregation between virgin and aged asphalt," Construction and Building Materials, vol. 221, pp. 301-307, 2019.

[53] M. Ahmadi and Z. Chen, "Insight into the interfacial behavior of surfactants and asphaltenes: molecular dynamics simulation study," Energy \& Fuels, vol. 34, no. 11, pp. 13536-13551, 2020.

[54] S. Song, H. Zhang, L. Sun, J. Shi, X. Cao, and S. Yuan, "Molecular dynamics study on aggregating behavior of asphaltene and resin in emulsified heavy oil droplets with sodium dodecyl sulfate," Energy \& Fuels, vol. 32, no. 12, pp. 12383-12393, 2018.

[55] G. Xu and H. Wang, "Diffusion and interaction mechanism of rejuvenating agent with virgin and recycled asphalt binder: a molecular dynamics study," Molecular Simulation, vol. 44, no. 17, pp. 1433-1443, 2018. 